\section{Usefulness of direct peroral cholangioscopy in the management of intrahepatic lithiasis}

Intrahepatic lithiasis is a rare condition in Western countries, and the majority of reported cases to date have been associated with extrahepatic biliary tract gallstones and hereditary cystic disorders, such as Caroli disease. The usual clinical presentation consists of repeated episodes of cholangitis, which can be complicated by liver abscess and sepsis. The management of intrahepatic gallstones is challenging. Surgical therapy has been the most effective approach; however, few cases have shown the effectiveness of management with percutaneous cholangioscopy $[1,2]$. The role of direct peroral cholangioscopy in the treatment of intrahepatic gallstones has not yet been assessed [3].

We present here the case of a 64-year-old woman admitted for acute cholangitis associated with segmental intrahepatic lithiasis. Her past medical history was remarkable for a recent hospital admission to treat acute cholangitis secondary to choledocholithiasis; endoscopic retrograde cholangiopancreatography (ERCP) had resulted in apparently complete removal of the gallstones.

During the current admission, magnetic resonance cholangiopancreatography (MRCP) revealed four gallstones of approximately $1 \mathrm{~cm}$ in the left intrahepatic bile duct above the hepatic hilum, with dilatation of the left intrahepatic and the common bile ducts ( $\bullet$ Fig. 1 ). Therapeutic ERCP resulted in the removal of only one of the gallstones. During subsequent direct peroral cholangioscopy with an Olympus GIF-Q180 gastroscope (Olympus America, Center Valley, Pennsylvania, USA), the remaining three gallstones were extracted (two with a removal balloon and the other with a "mouse tooth" grasping forceps under direct visualization) ( Fig. 2, $\bullet$ Fig.3).

The case presented here shows that direct cholangioscopy is possible in the setting of intrahepatic lithiasis. In conclusion,

\section{Paulo Massinha, MD}

massinha@iol.pt direct cholangioscopy is effective in the treatment of intrahepatic lithiasis and may be considered an alternative to surgery in selected cases, although only when performed in experienced centers.

\section{Endoscopy_UCTN_Code_TTT_1AR_2AH}

Competing interests: None

\section{Paulo Massinha, Nuno Nunes, Rodrigo Liberal, Filipa Ávila, Vera Santos, Ana Rego, José Renato Pereira, Nuno Paz, Maria Antónia Duarte}

Hospital do Divino Espírito Santo de Ponta Delgada, Department of Gastroenterology, Ponta Delgada, Portugal

\section{References}

1 Lee K, Kim H. Updates in the treatment of gallstones. Expert Rev Gastroenterol Hepatol 2009; 3: 649-660

2 Mori T, Sugiyama M, Atomi Y. Gallstone disease: management of intrahepatic stones. Best Pract Res Clin Gastroenterol 2006; 20: $1117-1137$

3 Yasuda I, Itoi T. Recent advances in endoscopic management of difficult bile duct stones. Dig Endosc 2013; 25: 376 - 385

\section{Bibliography}

DOI http://dx.doi.org/

10.1055/s-0034-1377952

Endoscopy 2014; 46: E553

(c) Georg Thieme Verlag KC

Stuttgart · New York

ISSN 0013-726X

\section{Corresponding author}

Hospital do Divino Espírito Santo de Ponta Delgada Department of Gastroenterology

Avenida D. Manuel I 9500-370 Ponta Delgada

Portugal

Fax: +351-296-203-090

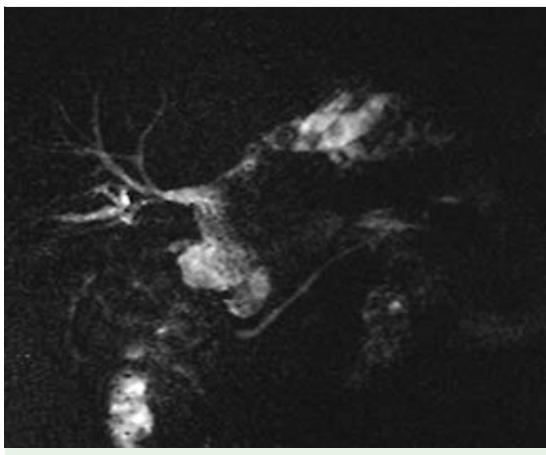

Fig. 1 Magnetic resonance cholangiopancreatography before direct peroral cholangioscopy reveals four gallstones in the left intrahepatic bile duct.

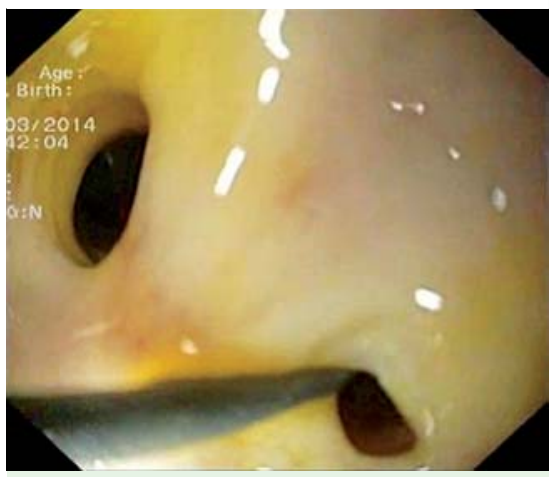

Fig. 2 Selective intrahepatic cannulation with a 0.035 -in guidewire.

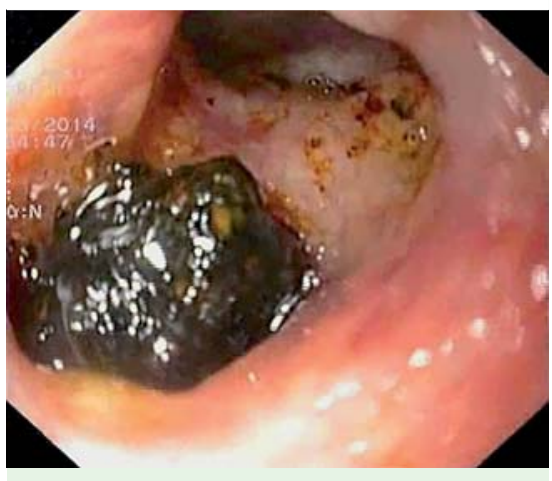

Fig.3 Intrahepatic gallstone. 